\title{
EFETIVAÇÃO DO DIREITO AO CASAMENTO ENTRE PESSOAS DO MESMO SEXO VIA CONTROLE CONSTITUCIONAL DIFUSO: DIREITO FUNDAMENTAL GARANTIDO NA CONSTITUIÇÃO DA REPÚBLICA FEDERATIVA BRASILEIRA DE 1988.
}

\section{Maria Clayde Alves Pace}

RESUMO: O artigo discute o direito ao acesso ao estado de casado, via matrimonial, pela aplicabilidade imediata do direito constitucional das pessoas do mesmo sexo, unidas por vínculos de afeto, celebrarem entre si casamento civil fazendo valer o direito universal de constituírem família, fundando sua pretensão na inconstitucionalidade de artigos do Código Civil Brasileiro vigente, bem como, demonstra a possibilidade da acessibilidade desses direitos positivos, por via da moderna hermenêutica constitucional orientadora da sistematicidade hierarquizadora dos valores e princípios constitucionais dentro da dialética racional do circulo sistêmico utilizando o controle de constitucionalidade difuso como meio eficaz da efetivação destes direitos constitucionais, auto aplicáveis às relações homo afetivas.

PALAVRAS-CHAVE: Dignidade e igualdade da pessoa humana. Sistema Constitucional e hermenêutica axiológica. Casamento entre pessoas do mesmo sexo. 


\section{NOTAS INICIAIS}

Ter um ponto de partida é o primeiro passo da viagem. É o que pretendemos demonstrar com o presente estudo. Como ponto de partida, tendo por candeeiro que há muito tempo nos ilumina, o rumo poético do mestre Fachin: "Partir para esta travessia mesmo com a consciência da incerteza e do acaso é a fonte que nos ilumina a matar a sede do que não tem nome e a saciar a fome da utopia que escreve o amanhã."

O estudo busca refletir a realidade do fato social: uniões afetivas entre pessoas do mesmo sexo, que se vêem privadas ou cerceadas em seu Direito Constitucional de fundar família matrimonializada, pelo instituto do casamento civil previsto no CCB/2002.

A temática é polêmica, porém não pode mais deixar à margem do sistema normativo positivo, a vida de relações de milhões de cidadãos brasileiros que desejam ter as suas relações afetivas reconhecidas pelo Estado eis que produzem efeitos imperativos e vinculantes na vida desta parcela social, no trato com o parceiro(a), com terceiros, com a sociedade e com Estado.

O estudo exige, para o reconhecimento deste direito, a efetividade do Direito Constitucional da Dignidade e da Igualdade da pessoa humana, nos mesmos moldes do direito ao casamento deferido às pessoas heterossexuais fundando família matrimonializada.

Para tanto, num primeiro momento, teceremos apontamentos sobre os valores e os princípios constitucionais da dignidade e da igualdade da pessoa humana; sobre princípios e regras constitucionais e a colisão entre princípios constitucionais e as antinomias entre regras constitucionais estritas. Tentaremos demonstrar a sistematicidade do Direito Constitucional por via da hermenêutica sistêmica axiológica hierarquizadora, e ainda a eficácia do instrumento de controle difuso de constitucionalidade como meio de efetivação do direito ao acesso ao instituto do casamento civil.

\footnotetext{
${ }^{1}$ FACHIN, Luiz Edson. CURSO DE DIREITO DE FAMÍLIA.Elementos críticos à luz do novo Código Civil brasileiro. Ricardo Pereira Lima (coord.) 2ª ed. Rio de Janeiro: Renovar. 2003. p.10.
} 
$\mathrm{Na}$ seqüência, abordaremos alguns aspectos que entendemos relevantes, sem a exclusão de outros tantos, e sob tal batuta, a discussão da inconstitucionalidade dos artigos 1514; 1517 e 1565 do atual Código Civil Brasileiro bem como a interpretação que entendemos equivocada, em parte, pela doutrina, do $\S 3^{\circ}$ do art.226, da CRFB/88, como um dos óbices elencados, no sentido de impossibilitar ou obstar, o casamento civil entre pessoas do mesmo sexo.

Nesta quadra, também tentaremos demonstrar que não há impedimento taxativo no artigo específico n.1521 do CCB/2002, que trata dos impedimentos explícitos ao acesso do estado de casado, para esta parcela de brasileiros que ainda esperam alcançar a plena cidadania por via da sistemática constitucional e 0 descompasso, sobre o tema, do CCB/2002 em face à Carta Constitucional eminentemente principiológica de 1988.

$\mathrm{Na}$ parte final do estudo, procuraremos demonstrar a inexistência de impedimento legal ao casamento entre pessoas do mesmo sexo na sistemática constitucional em relação com o sistema como um todo, harmônico e axiológico, para a plena realização da sociedade justa e igualitária prevista na Carta Magna. Ao final, breves considerações encerram a discussão.

\section{DIGNIDADE DA PESSOA HUMANA E A CARTA CONSTITUCIONAL DE 1988.}

A Carta Constitucional de $1988^{2}$ tem como um de seus fundamentos, a dignidade da pessoa humana e a prevalência dos princípios da supremacia dos Direitos Humanos na ordem nacional e internacional. ${ }^{3} \mathrm{Com}$ efeito, tratar de tal tema nos reporta aos primórdios do movimento chamado lluminismo ${ }^{4}$, tendo como marco teórico, os primados da Declaração de Direitos do Bom Povo da Virgínia ${ }^{5} e$ da Declaração Dos Direitos do Homem e do Cidadão de $1789{ }^{6}$ que "tinha como

\footnotetext{
2 BRASIL. Constituição Federal. Art.1ํㅡ. III.

${ }^{3}$ BRASIL. Constituição Federal. Art. 4ํㅡ, II.

${ }^{4}$ Século XVIII.

${ }^{5}$ SILVA, José Afonso da. Curso de Direito Constitucional. São Paulo: Malheiros. 9ª ed.1993. p.141.

${ }^{6}$ SILVA, José Afonso da. Curso...p.145. "O texto da Declaração de 1789 é de estilo lapidar, elegante, sintético, preciso e escorreito, que, em dezessete artigos, proclama os princípios da liberdade, da igualdade, da propriedade e da legalidade e as garantias liberais que ainda se encontram nas declarações contemporâneas."
} 
destinatários todo o gênero humano". ${ }^{7}$ Como sabemos, a Revolução Francesa, em 1789, foi um marco histórico, "um divisor de águas", no sentido da construção da cidadania universal, pautada pela Igualdade, Liberdade e Fraternidade, editando a Declaração Universal dos Direitos do Homem e do Cidadão. ${ }^{8}$

A Declaração Francesa de 1789 proclamou ser Direito do Povo, a Liberdade, Igualdade e Fraternidade assim, o principal legado da Revolução Francesa ainda atual, mesmo nos nossos conturbados dias foi a visão universal dos direitos do Homem e do Cidadão, como resultado dos preparativos da implantação do Estado Liberal levado a efeito pelos revolucionários franceses "As Declarações são obras do pensamento político, moral e social de todo o século XVIII."9

Em 1948, fundada nos princípios da Declaração Francesa, em 10 de Dezembro, a ONU, da qual o Brasil faz parte, editou a Declaração Universal dos Direitos Humanos, que traz no Preâmbulo o direcionamento para o qual os EstadosMembros deverão privilegiar e adotar em suas políticas públicas, pela valoração da vida humana em todas as suas dimensões. ${ }^{10}$ A Declaração de 1948 foi (re)afirmada e (re)ratificada, pela Declaração do Milênio da ONU, em 8 de Setembro de 2000, colocando as necessidades da pessoa humana no epicentro das políticas públicas. ${ }^{11}$ Consoante a Carta da Organização dos Estados Americanos, da qual o Brasil é signatário, inicialmente assinada em Bogotá em 1948 e, reformada por vários protocolos, sendo por último o protocolo de Manágua, em 1993 e, em vigor desde 25 de setembro de 1997, garante aos cidadãos dos Estados Membros, em seu primeiro

7 BONAVIDES, Paulo. Curso de Direito Constitucional. São Paulo: Malheiros. 2004. 14ª ed. p.562.

${ }^{8}$ DIREITOS HUMANOS NORMAS E CONVENÇÕES. Bauru, SP: Edipro. 2003. p. 11 e ss.

${ }^{9}$ SILVA, José Afonso. Curso...p.144

${ }^{10}$ VIEIRA, Jair Lot.(supervisor editorial) DIREITOS HUMANOS NORMAS E CONVENÇÕES. Bauru, SP: Edipro. 2003. p. 12 e p.42 “ A ASSEMBLÉIA PROCLAMA A PRESENTE DECLARAÇÃO UNIVERSAL DOS DIREITOS HUMANOS como ideal comum a atingir por todos os povos e todas as nações, a fim de que todos os indivíduos e todos os órgãos da sociedade, tendo-a constantemente no espírito, se esforcem, pelo ensino e pela educação, por desenvolver o respeito desses direitos e liberdades e por promover, por medidas progressivas de ordem nacional e internacional, o seu reconhecimento e a sua aplicação universais e efetivos tanto entre as populações dos próprios Estados Membros como entre as dos territórios colocados sob a sua jurisdição.[...] A Resolução $n^{\circ}$ 2.2000 - A (XXI) da ONU, de 16 de dezembro de 1966, editou o Pacto Internacional dos Direitos Civis e Políticos, ratificado pelo Brasil em 24 de janeiro de 1992, reafirma os direitos de liberdade e da não discriminação, em seu art.2‥” p.42

${ }^{11}$ VIEIRA. Jair Lot.(sup) DIREITOS HUMANOS NORMAS E CONVENÇÕES p.59 e DECLARAÇÃO DO MILÊNIO DA ONU, de 08 de Setembro de 2000. (...) para além das responsabilidades ss que todos temos perante as nossas sociedades, temos a responsabilidade coletiva de respeitar e defender os princípios da dignidade humana, da igualdade e da eqüidade, a nível mundial. 
Considerando, o direito inalienável dos homens, a um ambiente favorável para o desenvolvimento de sua personalidade e à realização de suas justas aspirações. ${ }^{12}$

Com efeito, as Declarações, sendo documentos com eficácia na ordem internacional, devem servir de instrumento de completude à efetividade dos direitos humanos, na ordem interna e externa. Elementar a distinção da categoria "todos os homens", insculpida na Declaração Universal dos Direitos Humanos, com a de "todo ser humano" ou de "todas as pessoas" inscrita na Declaração Universal dos Direitos dos Povos. Deflui deste documento ${ }^{13}$ que todo o gênero humano está contemplado na proteção destinada à pessoa. ata de 1966, a preparação dos Pactos das Nações Unidas sobre direitos civis e políticos, econômicos e sociais ${ }^{14}$ dos quais advieram, posteriormente, na Europa, a Convenção Européia sobre os Direitos do Homem e, nas Américas, em 1969, o Pacto de São José da Costa Rica ${ }^{15}$ que contempla a instituição da Corte Interamericana de Direitos Humanos. ${ }^{16}$

Sustenta a assertiva, o artigo 20 da Declaração Universal dos Direitos dos Povos ao determinar que, todas a minorias co-existam e gozem dos mesmo direitos que os demais cidadãos, no seio de um Estado. Em consonância com ordenamento internacional pelos Tratados, Convenções e Pactos ratificados pelo Brasil, a CRFB/88 determinou, através do constituinte originário de 1986 que, em todas as

12 VIEIRA. Jair Lot. DIREITOS HUMANOS NORMAS E CONVENÇÕES p.181 e 182, com as seguintes orientações: "Os Estados Americanos signatários da presente Convenção. Reafirmando seu propósito de consolidar neste Continente, dentro do Quadro das instituições democráticas, um regime de liberdade pessoal e de justiça social, fundado no respeito dos direitos humanos essenciais; Art.1‥ Obrigação de respeitar os direitos: Os Estados Partes nesta Convenção comprometem-se a respeitar os direitos e liberdades nela reconhecidos e a garantir seu livre e pleno exercício a toda pessoa que esteja sob a sua jurisdição, sem discriminação alguma, por motivo de raça, cor, sexo, idioma, religião, opiniões políticas ou de qualquer natureza, origem nacional ou social, posição econômica, nascimento ou qualquer outra condição. (grifos nossos)

${ }^{13}$ REZEK, Francisco. CURSO ELEMENTAR DE DIREITO INTERNACIONAL PÚBLICO, 9a ed. São Paulo: Saraiva, 2002, p.211Como informa o mestre Francisco Rezek em seu curso, lembrando a natureza não convencional da Declaração e ainda, que esta não contêm a força de Tratado, tendo sido adotada sob a forma de resolução.

\footnotetext{
${ }^{14}$ Rezek, Francisco. Curso Elementar...p.213.

${ }^{15}$ Convenção ratificado pelo Brasil, em 1992 sediada a CIDH em São José da Costa Rica.

16 Como aponta Antonio Augusto Cançado Trindade, “ A Declaração enfatizou sobretudo a trilogia direitos humanos/democracia/desenvolvimento em seus múltiplos aspectos (...) e da identificação dos obstáculos aos direitos humanos(parágrafos 10 e 21). In Tratado de Direito Internacional dos Direitos Humanos. V.I. Porto
} Alegre:Sergio Antonio Fabris Editor, 1997, p.135. 
políticas públicas a serem implementadas, o valor da pessoa humana deverá ser o norte condutor destas medidas. ${ }^{17}$

O exercício dos direitos sociais e individuais, bem como a liberdade, a segurança, o bem-estar, o desenvolvimento, a igualdade e a justiça foram eleitos, pelo constituinte originário, no Preâmbulo da Constituição Federal de 1988, como valores supremos da sociedade (dita) fraterna, pluralista e sem preconceitos. ${ }^{18} \mathrm{O}$ constituinte, ao tratar dos princípios fundamentais da Republica Federativa do Brasil, afirma que ela se constitui um Estado Democrático de Direito e, no Art.1ํㅡ, III da CRFB $/ 88^{19}$, afirma que um dos fundamentos da nossa organização política e social é a Dignidade da Pessoa Humana.

O teor do Art.3ํ, IV, da CRFB/88, verificamos que um dos objetivos fundamentais da República a ser perseguido pelo Estado e pela Sociedade é promover o bem de todos e erradicar toda e qualquer forma de discriminação. Com efeito, escudados no Art.5ำ, caput, da CRFB/88 inconteste a orientação do constituinte, no sentido de que a sociedade brasileira e, igualmente o Estado, através de seus três poderes, devam pautar sua decisões, pela não discriminação de qualquer natureza. Ainda, inserto e garantido no inciso X, do Art.5ำ da CFRB/88, a inviolabilidade do direito a intimidade, a vida privada, a honra e imagem das pessoas, assegurado o direito a indenização pela violação dos mesmos.

Destarte, a par destes instrumentos jurídicos, poder-se-ia afirmar que todo este arcabouço nacional e universal sustenta e garante o tratamento digno e igualitário entre nós, mas como é facilmente demonstrável, assim não ocorre em nossa sociedade, desigual e injusta.

Para adentrarmos ao tema, necessário descobrir a quais grupos de pessoas ou a qual pessoa nos referimos. Incessantemente, o "coral da inquietude"20 atormenta o pesquisador e a inquietação fomenta perguntas tais como: quem é a

${ }^{17}$ BRASIL. Constituição Federal. Art.5‥ Caput.

18 BRASIL. Constituição Federal. "PREÂMBULO: Nós, representantes do povo brasileiro, reunidos em Assembléia Nacional constituinte para instituir um Estado Democrático, destinado a assegurar o exercício dos direitos sociais e individuais, a liberdade, a segurança, o bem-estar, o desenvolvimento, a igualdade e a justiça como valores supremos de uma sociedade fraterna pluralista e sem preconceitos, fundada na harmonia social e comprometida, na ordem interna e internacional, com a solução pacífica das controvérsias, promulgamos, sob a proteção de Deus, a seguinte CONSTITUIÇÃO DA REPÚBLICA FEDERATIVA DO BRASIL"

19 Constituição da República Federativa do Brasil.

${ }^{20}$ BROUSSAR, Domenico Corradini.Corale dell” inquietude. Tradução de Roseli de Jesus BotelhoLongo. Curitiba: EDIBEJ. 1997. 
pessoa humana? A partir de que momento histórico surgem as preocupações com este ser universal? A que tipos humanos as normas se destinam? Que tipos de normas?

Os subsídios à investigação são obtidos pelas elucidações de Comparato ao asseverar que as respostas foram dadas "sucessivamente, no campo da religião, da filosofia e da ciência"21 e que a prevalência do ser humano no planeta se deu pela afirmação da fé monoteísta. ${ }^{22} \mathrm{~A}$ transposição da explicação religiosa para a filosófica se dá pela sabedoria grega ${ }^{23}$, e conforme Comparato, citando Prometeu Acorrentado (445-470), nas palavras de Ésquilo para o Titã "Ouça agora as misérias dos mortais e perceba como, de crianças que eram, eu os fiz seres da razão, capazes de pensar"24

É desta fase a afirmação da supremacia do homem no mundo por sua natureza racional. Apenas o homem indaga sobre a sua própria essência, o sentido reflexivo de sua existência, de sua vida e morte. Ao se dar conta do sentido da vida, o homem é capaz de discernir a justiça da injustiça; o belo do feio, a dignidade do aviltamento. É, pela sabedoria antiga, na fase axial ${ }^{25}$ da História, que se exprime um sentido valorativo à existência deste ser, com a organização de um catálogo de valores que vai aos poucos se explicando e se ampliando. ${ }^{26}$ Afirma Comparato que foi neste período que se deu a gênese do direito da igualdade, nas palavras do mestre.

\footnotetext{
${ }^{21}$ COMPARATO. Fábio Konder. A AFIRMAÇÃO HISTÓRICA DOS DIREITOS HUMANOS. 3ª ed. São Paulo: Saraiva.2004. p.1

22 COMPARATO. A afirmação histórica...p.1

23 DURANT, Wil. História da Civilização. Tradução de Gulnara de Morais Lobato revista por Monteiro Lobato, $3^{\text {a }}$ edição. São Paulo: Companhia Editora Nacional, $2^{\underline{a}}$ parte, tomo 1ำ p.176 "A filosofia nasce a partir da fusão do realismo natural dos mercadores fenícios e gregos em encontro com a sabedoria dos sacerdotes egípcios e dos Magi persas, dos profetas hindus, a ciência dos sacerdotes dos caudeus, a cosmogonia de Hesído que se encontravam em Mileto, na Grécia, e deste encontro de idéias nasce a noção de Lei”

${ }^{24}$ COMPARATO, Fábio Konder. A afirmação histórica...p.3.

${ }^{25}$ COMPARATO, Fábio Konder. A Afirmação histórica ...p.8 e 9 esclarece: “ Karl Jaspers sustentou que o curso da História poderia ser dividido em duas etapas, em função de uma determinada época, entre os séculos VIII e II a.C., a qual formaria, por assim dizer, o eixo histórico da humanidade. Daí a sua designação, para essa época, de período axial (Achsenzeit).No centro do período axial, entre 600 a 480 A.C., coexistiram, sem se comunicarem ente entre si, alguns dos maiores doutrinadores de todos os tempos:Zaratustra na Pérsia, Buda na Índia, Lao-Tsê e Confúncio na China, Pitágoras na Grécia e o Dêutero-Isaías em Israel. Todos eles, cada um a seu modo, foram autores de visões de mundo, a partir das quais estabeleceu-se a grande linha divisória história [...] Foi durante o período axial que se enunciaram os grandes princípios e se estabeleceram as diretrizes fundamentais de vida em vigor até hoje."
}

${ }^{26}$ COMPARATO. A afirmação histórica...p.5 
[...] partir do período axial que, pela primeira vez na História, o ser humano passa a ser considerado, em sua igualdade essencial, como ser dotado de liberdade e razão, não obstante as múltiplas diferenças de sexo, raça, religião ou costumes sociais. Lançavam-se assim, os fundamentos intelectuais para a compreensão da pessoa humana e para a firmação da existência de direitos universais, porque a ela inerentes.[...] essa convicção de que todos os seres humanos têm direito a serem igualmente respeitados, pelo simples fato de sua humanidade, nasce vinculada a uma instituição de capital importância: a lei escrita, como regra geral e uniforme, igualmente aplicável a todos os indivíduos que vivem numa sociedade organizada ${ }^{27}$

Ainda, no mesmo sentido seguindo a linha do pensamento Kantiano aponta, com propriedade Comparato:

[...] se o fim natural de todos os homens é a realização de sua própria felicidade, não basta agir de modo a não prejudicar ninguém. Isto seria uma máxima meramente negativa. Tratar a humanidade como um fim em si implica o dever de favorecer, tanto quanto possível, o fim de outrem. Pois sendo o sujeito um fim em si mesmo, é preciso que os fins de outrem sejam por mim considerados também como meus. ${ }^{28}$

A justificativa científica para afirmar a supremacia deste homem criado por Deus, indagado pela Filosofia, se deu com o advento da teoria da evolução dos seres vivos, de Charles Darwin. ${ }^{29} \mathrm{O}$ homem ocupa o topo da cadeia evolutiva das espécies e, por este fato, ele indaga a si mesmo, quem é este homem? Este Ser é único, porém em constante transformação, é um vir a ser, em movimentação, voltado para a auto-organização do sistema universal, dado o caráter evolutivo da espécie, sofrendo, neste processo, todas as influências do meio social, da cosmologia, da geologia e biologia. É um ser incompleto e inacabado, é um constante devir.

\section{SISTEMA CONSTITUCIONAL E FAMÍLIA FUNDADA NO CASAMENTO.}

O fenômeno da vida em sociedade, não se aparta da vida de relações que se realiza dentro de um sistema social. E, como soer ocorrer mesmo na natureza em

${ }^{27}$ COMPARATO. A Afirmação Histórica...p.11 e 12.

${ }^{28}$ COMPARATO. A Afirmação Histórica...p.23

29 apud Comparato, op.cit.p.no sentido de que a natureza, após sucessivas tentativas frustradas encontrou, por acaso, a via da evolução das espécies, ocupando o homem o topo da cadeia evolutiva, pela própria dinâmica evolutiva. 
estado bruto, biológica, animal, as relações se desenvolvem dentro de um sistema ordenado, ou não, através das relações jurídicas que são concretizadas pela interação das normas.

A sociedade, como um sistema, encerra em si mesma a causa e o efeito ${ }^{30}$ "fundante de tudo o que acontece"31.Com efeito, em Luhmann, apontado por Duarte, verificamos que os sistemas sociais são autopoiéticos, ou seja, se auto-constroem dentro do seu ambiente através de sistemas de comunicação, dependendo do entorno, pois:

A sociedade é um sistema de comunicação, ou seja, composta de comunicações e só destas. Seus elementos fundantes não são os indivíduos e sim, as comunicações.(...) os indivíduos não são mais considerados os elementos naturais da sociedade que a constituem e a transformam. Os indivíduos, para a Teoria dos Sistemas, constituem o ambiente da sociedade na medida em que eles, por sua vez, são sistemas (sistemas orgânicos autopoiéticos). ${ }^{32}$

Com efeito, neste diapasão, comungamos das idéias de Cambacéres quando afirma que para que o sistema jurídico dê conta do seu objeto, ele deve satisfazer os três princípios fundamentais para cumprir as três exigências que o homem tem na sociedade: “a) ser senhor da própria pessoa; b) possuir bens para poder satisfazer as próprias necessidades e c) poder dispor desses bens no interesse próprio e da própria família." 33

Pois bem, a CRFB/88 é essencialmente uma carta principiológica como já asseverado por Canotilho ${ }^{34}$ tendo por um de seus fundamentos ${ }^{35}$ a Dignidade da pessoa humana.

30 SERRANO, José Luis. "Para entender esto podemos poner el ejemplo de uma frontera: podemos decir que la línea teriza separa/une a dos países. Unimos dos verbos contradictorios (separar y unir) y sin embargo la frase tiene sentido" VALIDEZ Y VIGENCIA. APROXIMACIÓN GARANTISTA A LA TEORIA DE LA NORMA JURÍDICA. Granada:1998, I \& 100, 4.3 p.25.

${ }^{31}$ DUARTE, Francisco Carlos. JUSTIÇA \& DECISÃO: Teoria da decisão judicial. Curitiba: Juruá.2002.

32 DUARTE, op. cit.p. 25

33 Apud BOBBIO, p. 70

34 CANOTILHO, J.J. Gomes. DIREITO CONSTITUCIONAL. 6aㅗ ed. Coimbra: Livraria Almedina. 1993, p. 180 a 182.

${ }^{35}$ Que para os efeitos deste estudo tem um significante diferente de princípios fundamentais no sentido de que fundamento é uma das pilastras mestras da construção do edifício ESTADO DEMOCRÁTICO DE DIREITO e na ausência da efetividade deste fundamento, o próprio Estado tem sua fundação abalada e poderá ruir diante dos gravames sociais que esta ausência causará. 
Nenhuma pessoa pode ter plena cidadania quando seus direitos não são respeitados pela sociedade em que ela vive como membro do pacto social e, neste sentido, disciplinar as relações afetivas apenas para uma parcela da sociedade, os heterossexuais, é um desrespeito à dignidade da pessoa humana, via de conseqüência, ela sofre a discriminação e, portanto não goza de plena cidadania pois a vida afetiva dos seres humanos, quando em vida de relações, produzem efeitos jurídicos na esfera social e este afeto deve ser tutelado pelo Estado, sem discriminação de qualquer natureza em igualdade entre todos os membros do pacto.

No tecido social é sólida a cultura de que a família constituída a partir do casamento é superior às demais, o que veio a ser ratificado pelo legislador constituinte de 1988, não obstante o progresso obtido de igualdade de tratamento aos demais modelos de "entidades familiares". ${ }^{36}$ Igualou os direitos entre os membros dos grupos familiais, suprimindo a supremacia masculina do pater família ou cabeça do casal (art.226, § 5 da CFRB/88) atendendo aos reclamos sociais de tratamento igualitário entre os sexos.

As relações afetivas homossexuais em nada diferem das dos heterossexuais pois hodiernamente, a família matrimonializada não tem mais o cunho patriarcal e sim é constituída visando a felicidade dos seres que adentram a este instituto a denominada família eudemonista. Verifica-se o grau de hierarquia superior conferido ao modelo familiar fundado no casamento, colocando os demais em um degrau abaixo, ou seja, um desvalor ao modelo tido como legal como se fossem famílias de segunda classe ${ }^{37}$.

Podemos inferir que deste espírito está imbuído o Art. 226, caput, da CRFB/88. Posteriormente, o novo Código Civil brasileiro, Lei 10.406 de 10.01.2002, no capítulo de direito de família, especialmente, sobre o instituto do casamento, veio,

${ }^{36}$ BRASIL. Constituição Federal. 35aㅗ ed. São Paulo: Saraiva.2005. Art.226 da CF/88. A família, base da sociedade, tem especial proteção do Estado.

37 PACE, Maria Clayde Alves. CASAMENTO ENTRE PESSOAS DO MESMO SEXO: direito garantido no sistema constitucional brasileiro. ARTIGO apresentado no XIV ENCONTRO PREPARATÓRIO CONPEDI INIVEM. Marília/SP., em 25/05/2005. 
em parte num retrocesso, repetindo o Código de 1916, e porque comungamos do mesmo entendimento, a feliz demonstração de Fachin. ${ }^{38}$

A família atual é fundada no afeto, tem a sua ratio no sentimento amoroso entre os membros do grupo. Porém ainda permanece o conceito de família legítima baseado no casamento, e as ilegítimas ou naturais, ou seja, as "entidades familiares", como dissemos, famílias de segunda classe. ${ }^{39}$

A família fundada no casamento produz efeitos jurídicos, pessoais e patrimoniais diferentes dos efeitos jurídicos apriorísticamente atribuídos às famílias naturais (união estável) e da família monoparental, principalmente no tocante a alimentos, direitos previdenciários e direitos sucessórios, traduzindo as disposições legislativas infraconstitucionais, em discriminação odiosa em relação aos cônjuges e aos membros do grupo dos chamados modelos "entidades familiares". Famílias de segunda classe.

O legislador do CCB de 2002, não se ateve a estas profundas alterações ${ }^{40}$, mormente a constitucionalização dos direitos de família, mantendo no "novo" Código, o que já era velho.

Na mesma toada, assinala Carbonera que, no direito pátrio contemporâneo, temos "dois modelos básicos de família no Direito de Família (...) o patriarcal e o

${ }^{38}$ FACHIN, Luis Edson. TEORIA CRÍTICA DO DIREITO CIVIL. Rio de Janeiro: Renovar. 2000. p.9. que assim se manifesta: "É o inegável envelhecimento do que já nasceu passado, pois foi parido de costas para o presente. Outro horizonte, inquietante e interrogativo, bate às portas cerradas do sistema. O medievo que emoldura os institutos do status quo se mostra em pânico pois, à medida que o civilismo pretensamente neutro se assimilou aos servilismo burocrata doutrinário e jurisprudencial, não conseguiu disfarçar que não responde aos fatos e às situações que brotam da realidade contemporânea."

${ }^{39}$ GOMES, Orlando. DIREITO DE FAMÍLIA. 7ª ed. Rio de Janeiro: Forense. 1993. p.39-40, constando "Nos Códigos, dirigem-se as regras à família legítima, que se constitui, unicamente, pelo casamento. Regulam as relações pessoais e patrimoniais entre os cônjuges, estabelecidas como efeitos jurídicos do matrimônio. A filiação, o parentesco, o pátrio-poder são ordenados para a família legitimamente fundada(...) o comércio sexual fora do casamento é apenas considerado forma anormal de relações dessa natureza. Quando apresenta os caracteres de duração e estabilidade, vem-se admitindo que essa união, com a aparência de casamento, resulta a família natural. (...) Pouco importa,entretanto, que, na terminologia jurídica, o vocábulo família se reserve ao grupo constituído pelo matrimônio."

${ }^{40}$ LEITE, Eduardo de Oliveira.ORIGEM E EVOLUÇÃO DO CASAMENTO in TRATADO DE DIREITO DE FAMíLIA. Curitiba: Juruá. Vol. 1. 1991, p.295 ponderando com a sua sabedoria impar: " Onde há amor não há lugar para autoritarismo, nem hierarquia, a submissão desaparece e, pela primeira vez na história da humanidade, surge um maior espaço ao amor com uma tímida, mas nítida, busca de satisfação pessoal, realização íntima gerando uma nova concepção do casamento, com espaço mesmo ao prazer." 
eudemonista", ${ }^{41}$ orientando que a família eudemonista é aquela fundada na admissão da felicidade individual ou coletiva, a razão de ser da conduta humana moral. ${ }^{42} \mathrm{~A}$ família constitucionalizada é o modelo de família eudemonista, pois visa à felicidade da pessoa, dentro da unidade familiar. .

Com efeito, nesta construção "do ninho familiar"43 se estabelecem relações jurídicas, com terceiros e entre os sujeitos diretamente envolvidos. Por este privilégio na lei, a matrimonialização, a família fundada no casamento, tem suas relações jurídicas totalmente disciplinadas, a priori, pelo legislador do Código Civil traduzindo uma discriminação em relação aos outros modelos. Nos demais modelos familiares igualmente fundados no afeto, as relações e os efeitos jurídicos, para serem reconhecidos, deverão ab initio ser provados, quando da sua dissolução, buscando, inevitavelmente, às portas do judiciário, o que importa dizer, passar pelo calvário das lides forenses em intermináveis, dias, meses e até anos, de desgaste e

41 CARBONERA, Silvana Maria.O PAPEL JURÍDICO DO AFETO NAS RELAÇÕES DE FAMÍLIA. In: REPENSANDO FUNDAMENTOS DO DIREITO CIVIL CONTEMPORÃNEO. FACHIN, Luiz Edson ( Org.).Rio de Janeiro: Renovar.1998. p. 274.

42 CARBONERA, O PAPEL JURÍDICO... p.274, nota de rodapé no 1. Com efeito, suas palavras dão idéia exata desta transformação pontuando," (...) a noção de afeto, como um elemento concreto a ser considerado nas relações de família, foi ingressando gradativamente no jurídico, assim como outras tantas: liberdade, igualdade, solidariedade. Isto se deve às transformações pelas quais ela passou, especialmente quanto ao deslocamento do centro das preocupações: da instituição família para aqueles que a compõem. partir do momento em que o sujeito passou a ocupar uma posição central, era esperado que novos elementos ingressassem na esfera jurídica. E, foi o que se observou com relação ao afeto. A vontade de estar e de permanecer junto a outra pessoa revelou-se um elemento de grande importância tanto na constituição de uma família, assim como em sua dissolução. As pessoas passaram a se preocupar mais com o que sentiam do que com a adequação de seus atos ao modelo jurídico."

43 FACHIN, Luiz Edson. DIREITO DE FAMÍLIA. Elementos críticos à luz do novo Código Civil brasileiro. 2a Ed. Rio de Janeiro: Renovar. 2003. p. 1, que assim se manifestou: "A vigência do novo Código Civil e o principiar do século XXI testemunham tempos frutíferos de inquietude, denunciam dilemas expostos na fratura social, arrostam a exclusão econômica e jurídica e apontam para novas situações sociais. Eis o nó em desate pela contemporaneidade, cujos elos se projetam da sociedade para o ninho familiar." 
constrangimento, físicos, psicológicos e financeiros, para obter a tutela jurisdicional. Por todos, veja-se do escólio de Berenice Dias. ${ }^{44}$

Assim, a família fundada no casamento, goza de privilégio de tratamento, diante $\underline{\text { da }}$ Lei e na Lei. Flagrante a inconstitucionalidade das regras do CCB/ $2002^{45}$, pois "uma comunidade de princípios aceita a integridade" ${ }^{46}$ na magistral acepção de Dworkin que cunhou este modelo de "uma comunidade de princípios."

Verifica-se, na realidade social, a dispensa de um tratamento desigual cometido pelo legislador infraconstitucional, uma desigualdade injustificada na norma, que afronta os princípios fundantes do sistema jurídico pátrio, no sentido da máxima valoração da pessoa humana, na construção da família cidadã ${ }^{48}$ conforme os princípios constitucionais.

Fundar uma família matrimonializada, sem discriminação de qualquer natureza $^{49}$ é direito soberano de qualquer pessoa humana, direito constitucional, deferido igualmente à sociedade em sua totalidade, sejam heterossexuais ou homossexuais, pois o amor e o afeto, não escolhem sexo para florescer.

${ }^{44}$ DIAS, Maria Berenice. UNIÃO HOMOSSEXUAL. O preconceito \& a Justiça. $2^{2}$ ed. Porto Alegre: Livraria do Advogado. 2001. p.19/20." "Na base de todo fato social existe um interesse merecedor de tutela, interesse que independe da orientação sexual de seus titulares. Em um estado democrático de direito, todos têm direito à vida, à liberdade e à proteção, e o Estado tem o dever de garantir o respeito à dignidade, à integridade física e à propriedade de todos.Enquanto, por injustificável omissão legiferante, não forem disciplinas as novas estruturas familiares que florescem independentemente da identificação do sexo do par, ninguém, muito menos os operadores do Direito, pode fechar os olhos a essas realidades. Em nome de uma postura conservadora, deixar de atribuir efeitos jurídicos às relações que, muito mais que uma sociedade de fato, constituem uma sociedade de afeto revela atitude preconceituosa e discriminatória (...) A garantia da cidadania passa pela garantia da expressão da sexualidade, e a liberdade de orientação sexual insere-se como uma afirmação dos direitos humanos em um estado que se diz democrático de direito."

45 BRASIL.VADE MECUM JURÍDICO 2005. Leme: RCN Editora. CCB/2002. art.1514; 1517 e 1565. p.169 a 172.

${ }^{46}$ DWORKIN, Ronald. O IMPÉRIO DO DIREITO. tradução de Jefferson Luiz Camargo. São Paulo. Martins Fontes.1999. p.258.

47 DWORKIN, Ronald. O IMPÉRIO DO DIREITO. tradução de Jefferson Luiz Camargo São Paulo. Martins Fontes.1999. p.256 e 257 e por fundamental ao entendimento que comungamos, colacionamos: " o modelo de princípios satisfaz todas as nossas condições, pelo menos tão bem quanto qualquer modelo poderia fazê-lo numa sociedade moralmente pluralista. Torna específicas as responsabilidades da cidadania: cada cidadão respeita os princípios do sentimento de eqüidade e de justiça da organização política vigentes em sua comunidade particular, que podem ser diferentes daqueles de outras comunidades.(...) Faz com que essas responsabilidades sejam inteiramente pessoais: exige que ninguém seja excluído; determina que, na política, estamos todos juntos para melhor ou para pior; que ninguém deve ser sacrificado, como os feridos em um campo de batalha, na cruzada pela justiça total."

${ }^{48}$ FACHIN, Luiz Edson. DIREITO DE FAMÍLIA. Elementos críticos à luz do novo Código Civil brasileiro. Rio de Janeiro: Renovar. 2003. p.5. 
As normas dos artigos 1.514; 1.517 e 1.565 do novo Código Civil de 2002, relativas ao casamento, afrontam os fundamentos do Estado Democrático de Direito Brasileiro, estruturado pela CRFB/88. Também afrontam, os princípios fundantes e fundamentais da dignidade da pessoa humana e da ordem constitucional obrigatória de tratamento igualitário, em face das pessoas do mesmo sexo que desejam formar família matrimonializada. Famílias de primeira classe.

Verificamos também, que a atual CRFB/88 é uma Carta principiológica, ou seja, elegeu os princípios fundamentais como cláusulas pétreas, como se depreende do $\S 1^{\circ}$ do Art. 5ำ combinado com o $\S 4^{\circ}$, inciso IV do art.60, todos da CFRB/88, ou seja, não serão objeto de emenda constitucional, as deliberações tendentes a abolir, entre outros, os direitos e garantias individuais. A dinâmica constitucional é sistêmica, uma unidade, deve ser compreendida no seu todo e não em compartimentos estanques. Portanto, forçoso concluir que os conflitos entre normas constitucionais deverão ser harmonizados pelo próprio sistema, pelo princípio máximo hierarquizador, o da unidade da Constituição.

\section{PRINCÍPIOS E REGRAS: SISTEMATICIDADE CONSTITUCIONAL E O SISTEMA INFRACONSTITUCIONAL.}

Verificamos que poderá haver colisão entre princípios e antinomias entre regras constitucionais, como pontua Barroso. ${ }^{50}$ Quando constado o conflito, como resolver o impasse sem ferir o sistema e a unidade da Constituição?

Para a teoria dworkiana, será princípio sempre quando a norma contiver maior peso, ou seja, uma razão justificadora forte que não prescinde de maiores explicações, ao passo que será uma regra, sempre que a norma não contiver este peso. ${ }^{51}$ Asim, podemos inferir que a diferença está na argumentação que se levará a cabo e, sobre qual tipo de normas estaremos tratando, pois os princípios são

${ }^{49}$ CRFB/88 .Art.3ำ, inciso IV, " Constituem objetivos fundamentais da República Federativa do Brasil. IV - promover o bem de todos, sem preconceitos de origem, raça, sexo, cor, idade e quaisquer outras formas de discriminação."

50 BARROSO, Luís Roberto. INTERPRETAÇÃO E APLICAÇÃO DA CONSTITUIÇÃO. 6ª ed. São Paulo: Saraiva. 2004. p. 198 no seguinte sentido: "Um lance de olhos sobre a Constituição brasileira de 1988 revela diversos pontos de tensão normativa, isto é, de proposições que consagram valores e bens jurídicos que se contrapõem e que devem ser harmonizados pelo intérprete."

51 DWORKIN, Ronald. LEVANDO OS DIREITOS A SÉRIO.Tradução de Nelson Boeira. São Paulo. Martins Fontes.2002. p. 42 
proposições que descrevem direitos ${ }^{52}$ que hierarquizados, topicamente, teremos a resposta sobre a norma em comento.

Por princípios, que Canotilho chama de verdadeiras normas, fazendo a distinção qualitativamente distintas que são as regras jurídicas, ${ }^{53}$ verificamos a existência de regras e princípios na Constituição, podemos afirmar a possibilidade de uma "descodificação, em termos de um constitucionalismo adequado (...) da estrutura sistêmica, isto é, possibilita a compreensão da constituição como sistema aberto de regras e princípios" 54

No caso do sistema jurídico constitucional brasileiro, a efetividade dos princípios fundantes e fundamentais da CRFB/88, interpretada de forma sistêmica, pelo princípio da unidade da Constituição e os valores que ela contém, acima das regras constitucionais estritas, resolver-se-á a antinomia, por uma ponderação como aponta Barroso. ${ }^{55}$

\section{CASAMENTO CIVIL ENTRE PESSOAS DO MESMO SEXO: DIREITO CONSTITUCIONAL GARANTIDO PELA CARTA DE 1988.}

O presente estudo trata da possibilidade de casamento civil entre duas pessoas do mesmo sexo, fundando uma família matrimonializada, desde o início da relação amorosa. Para esta pretensão não há vedação constitucional, pois o caput e

52 DWORKIN, Ronald. LEVANDO OS DIREITOS A SÉRIO. p.141

53 CANOTILHO,.J.J.GOMES. DIREITO CONSTITUCIONAL E TEORIA DA CONSTITUIÇÃO. $3^{\text {aeed. }}$ Coimbra: Almedina.1999. p.1087-1088. "Em primeiro lugar, os princípios são normas jurídicas impositivas de uma optimização, compatíveis com vários graus de concretização, consoante os condicionalismo fácticos e jurídicos; as regras são normas que prescrevem imperativamente uma exigência (impõem, permitem ou proíbem) que é ou não cumprida(...); a convivência dos princípios e conflitual (Zagrebelsky), a convivência de regras é antinômica; os princípios coexistem, as regras antinômicas excluem-se. Conseqüentemente, os princípios, ao constituírem exigências de optimização, permitem o balanceamento de valores e interesses (não obedecem, como as regras, à << lógica do tudo ou nada>>), consoante o seu peso e a ponderação de outros princípios eventualmente conflitantes; as regras não deixam espaço para qualquer outra solução, pois se uma regra vale (tem validade) deve cumpri-se na exacta medida das suas prescrições, nem mais, nem menos."

${ }^{54}$ CANOTILHO. DIREITO CONSTITUCIONAL E TEORIA DA CONSTITUIÇÃO. p. 1090 a 1093. 
os $\S \S 1^{\circ}$ e $2^{\circ}$, do Art.226 da CRFB/88, não oferecem impedimentos e o $\S 5^{\circ}$, do mesmo artigo, se refere a direitos de igualdade entre os cônjuges, homem e mulher, mas não obsta o casamento entre pessoas do mesmo sexo.

As regras dos artigos n. 1.514; 1.517 e 1.565 do Código Civil Brasileiro em vigor, referentes ao instituto do casamento, estão em flagrante confronto com os princípios fundantes e fundamentais da Constituição Federal em vigor. Ademais, a regra da Lei específica, o CCB/2002, no art.1521, que trata dos impedimentos absolutos para o casamento em nenhum dos incisos do artigo citado está previsto a igualdade dos sexos obstante ao estado de casado. ${ }^{56}$

A assertiva é fundamentada nos estudos de Freitas ${ }^{57}$, pela utilização de um "meta-critério" que ele aponta como sendo o princípio axiológico hierarquizador. Destarte, o meta-critério, nasce da conceituação que ele faz de sistema jurídico, sem o qual a compreensão não se clarifica, quanto a circularidade do sistema ou circularidade hermenêutica, operando com princípios, normas estritas (regras) e os valores contidos na Carta Constitucional. ${ }^{58}$

A dicção dos Art.1.514 - O casamento se realiza no momento em que o homem e a mulher manifestam, perante o juiz, a sua vontade de estabelecer vínculo conjugal, e o juiz os declara casados; a do Art.1.517. "O homem e a mulher com

${ }^{55}$ BARROSO, Luís Roberto. INTERPRETAÇÃO E APLICAÇÃO DA CONSTITUIÇÃO. p.200 e 2001 "O papel do princípio da unidade é o de reconhecer as contradições e tensões - reais ou imaginárias - que existam entre normas constitucionais e delimitar a força vinculante e o alcance de cada uma delas. Cabe-lhe, portanto, o papel de harmonização ou "otimização" das normas, na medida em que se tem de produzir um equilíbrio, sem jamais negar, por completo a eficácia de qualquer delas.(...)A doutrina mais tradicional divulga como mecanismo adequado à solução de tensões entre normas a chamada ponderação de bens ou valores, Trata-se de uma linha de raciocínio que procura identificar o bem jurídico tutelado por cada uma delas, associá-lo a um determinado valor, isto é, ao princípio constitucional ao qual se reconduz para, então, traçar o âmbito de incidência de cada norma."

${ }^{56}$ Como muito bem acentuado pelo douto Procurador da República, no município de Taubaté/SP, na Ação Civil Pública no 2005.61.18.000028-6, que tramita na 1aㅡ Vara Federal de Guaratinguetá/SP., Dr. JOÃO GILBERTO GONÇALVES FILHO que ingressou com a ação mencionada, nas corajosas e inteligentes ponderações, asseverando: " $O$ artigo 1521 do código civil reforça mais a tese de que a restrição existe apenas como resíduo de uma tradição cultural arcaica e preconceituosa, sendo inexistente em norma expressa. Até que poderia haver mais um inciso nesse artigo, assim disposto: "art.151(sic).Não podem casar: VIII - as pessoas do mesmo sexo", MAS NÃO HÁ." (...) Há que se reconhecer uma esfera, na intimidade privada dos indivíduos que as instituições oficiais não podem denegrir, nem por via indireta, negando aquisição de direitos.” p.37 (cópia digitada da inicial gentilmente cedida pelo Autor ao qual aproveitamos o ensejo e agradecemos imensamente).

${ }^{57}$ FREITAS, Juares. A INTERPRETAÇÃO SISTEMÁTICA DO DIREITO, p.114 e ss.

58 Como cediço, o Direito é um sistema de normas coexistindo harmonicamente entre si, como já apontamos. Destarte, os artigos 1514; 1517 e 1565 do CCB/2002 juntamente com o § 3ํ do art.226 da CRFB/88 devem ser compatibilizados com o preâmbulo; art. $1^{\circ}$,incisos II,III,IV e V; artigo $3^{\circ}$, caput e incisos; art.4 ${ }^{\circ}$, inciso II;

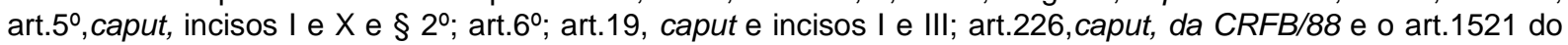
CCB/2002. 
dezesseis anos podem casar", no mesmo sentido arrastam consigo a regra do Art.1.565, todos do CCB/2002, todas são regras discriminadoras quando elegem os gêneros "homem-mulher" como únicos aptos a se casarem, desconsiderando o legislador, na formulação da norma-regra infraconstitucional, a correta interpretação do art.5ำ, caput, da CRFB/88, que disciplina. Todos são iguais perante a lei, sem distinção de qualquer natureza. As regras do CCB/2002 impugnadas distinguem onde a CRFB/88 não permite, pois os homossexuais também são cidadãos brasileiros e podem, acaso queiram, casar com pessoa de sua eleição, sem discriminação em fator do sexo escolhido para orientar o seu desejo amoroso. ${ }^{59}$

Via de conseqüência, o direito a tratamento igual é um dos atributos do direito da Dignidade da Pessoa Humana que, no nosso sistema, é um dos pilares do Estado Democrático de Direito, pela sistemática constitucional, assim, onde a Dignidade de qualquer ser humano não for respeitada, não estaremos diante de um Estado Democrático de Direito, pluralista e igualitário. Frusta-se a existência do próprio Estado, por ausência de um dos seus fundamentos. Elegendo e hierarquizando o fundante princípio da Dignidade da Pessoa Humana, no topo da sistemática hermenêutica axiológica, as regras do CCB/2002 em comento são inconstitucionais e devem se afastadas do ordenamento jurídico, seja pelo controle difuso, seja pelo controle concentrado de constitucionalidade, como se manifesta com a elegância de sempre, o mestre Barroso:

[...] o controle de constitucionalidade pode ser exercido pelo órgão político ou pelo órgão judicial. O controle será preventivo quando realizado pelo Legislativo ou pelo Executivo e ainda, por via de Mandado de Segurança, no órgão judicial. No controle repressivo, será sempre pela via judicial, "quando a lei já está em vigor, e destina-se a paralisar-lhe a eficácia (...) Em qualquer caso, havendo controvérsia sobre a interpretação de uma norma inconstitucional, a última palavra é do Judiciário. [...] o controle é difuso quando permite a todo e qualquer juiz ou tribunal o reconhecimento da inconstitucionalidade de uma norma e, conseqüentemente, sua não-aplicação ao caso concreto levado ao conhecimento da corte.[..] No Brasil, a Emenda Constitucional 16, de 06 de dezembro de 1965, introduziu o controle concentrado de constitucionalidade, perante o Superior Tribunal Federal, mediante a representação do Procurador-Geral da República, também chamada de ação genérica.

59 RIOS, Roger Raupp. A HOMOSSEXUALIDADE NO DIREITO. Porto Alegre: Livraria do Advogado e ESMAFE. 2001. p.26. "Discutir a discriminação por orientação sexual é cuidar exatamente disso: em que situações a existência de distintos regimes jurídicos justifica-se pela identidade atribuída a alguém em virtude da direção de seu desejo e/ou condutas sexuais, seja para outra pessoa do mesmo sexo (homossexualidade), do sexo oposto (heterossexualidade) ou de ambos os sexos(bissexualidade)." 
Isto porque já existia no sistema brasileiro a ação interventiva, igualmente de competência concentrada do Supremo Tribunal Federal, que figurava como pressuposto da decretação da intervenção federal nos Estados, em determinados casos. ${ }^{60}$

Assim, não se torna factível e jurídico que uma expressiva parcela da sociedade brasileira, em torno de $10 \%$ (dez por cento) ${ }^{61}$ tenham seus direitos constitucionais cerceados, por pré-conceitos morais que informam o legislador infraconstitucional orientado pela maioria heterossexual.

Utilizando do instrumento de controle difuso da constitucionalidade, entendemos que a possibilidade de se pleitear junto ao judiciário, a inconstitucionalidade dos artigos do CCB/2002 supra comentados é imediata e poderão, amparados na $\mathrm{CRFB} / 88$, os interessados se habilitarem ao casamento e acaso haja negativa, utilizarem a via judicial para ver declarado o seu direito constitucional, como um tribuno à cidadania, à dignidade e a igualdade, nos Estado Democrático Brasileiro.

\section{CONSIDERAÇÕES FINAIS.}

O percurso desenvolvido procurou demonstrar a polêmica do tema esposado, bem como as dificuldades, na práxis diária dos operadores do Direito que tal postulado irá encontrar ao adentrar as portas do judiciário.

A cultura e os costumes enraizados na sociedade brasileira, desde a colonização, por Portugal, até os anos 60 do século passado fundados nos conceitos do Direito Canônico, não souberam aproveitar as luzes do iluminismo que despontavam, à época, no velho continente. Implantaram na alma e nos corações da cultura e costumes do povo em formação, falsos conceitos morais já em decadência nos países mais cultos da Europa, notadamente, os do norte, de origem germânica, minimamente atingidos pelos preceitos da Igreja Católica e pelo Concílio de Trento.

Assim verificamos que existe no tecido social, uma parcela de indivíduos que são diariamente discriminados, humilhados e que, no mais das vezes ocultam sua verdadeira orientação sexual, por força do preconceito de que são alvos. Mas, o

\footnotetext{
${ }^{60}$ BARROSO, Luís Roberto. O CONTROLE DE CONSTITUCIONALIDADE NO DIREITO BRASILEIRO. São Paulo: Saraiva. 2004, p. 39 a 49

${ }^{61}$ MATOS, Ana Carla Harmatiuk. UNIÃO ENTRE PESSOAS DO MESMO SEXO: aspectos jurídicos e sociais. Belo Horizonte: Del Rey. 2004. p.2.
} 
constituinte atento à evolução social, houve por bem em não deixar taxativa, qualquer proibição para o casamento e formação de famílias entre pessoas do mesmo sexo. Havendo, até esta quadra, no nosso entender, equívocos de interpretações e orientações doutrinárias, que não souberam "ouvir e ver" a realidade social, os fatos da vida.

A análise procurou demonstrar que não há regra infraconstitucional proibitiva explícita e, acaso houvesse, esta também seria inconstitucional, em face dos Valores e Princípios fundantes e fundamentais existentes no harmônico e coerente sistema axiológico Constitucional Brasileiro. Assim, por via do controle difuso colocado ao julgador primievo, eis que tal controle pode ser exercido em todos os níveis no poder judiciário estaremos diante da concretude do que Freitas chamou de "meta-critério" o da Justiça. Cremos firmemente nesta possibilidade pelo uso da interpretação hermenêutica, pela sua circularidade sistêmica. ${ }^{62}$

A utopia, já salientou o mestre Herkenhoff ${ }^{63}$ é o pensamento em ação, vamos todos, unidos, trabalhar na construção desta sociedade, sem exclusões.

\section{REFERÊNCIAS BIBLIOGRÁFICAS.}

BARROSO, Luís Roberto. INTERPRETAÇÃO E APLICAÇÃO DA CONSTITUIÇÃO. $6^{\underline{a}}$ ed. São Paulo: Saraiva. 2004.

O CONTROLE DE CONSTITUCIONALIDADE NO DIREITO BRASILEIRO. São Paulo:

Saraiva. 2004.

BRASIL. Constituição Federal. 35ª ed. São Paulo: Saraiva. 2005.

BRASIL.VADE MECUM JURÍDICO 2005. Leme: RCN Editora. 2005

CANOTILHO, J. J. Gomes. DIREITO CONSTITUCIONAL. 6aㅡ ed. Coimbra: Livraria Almedina. 1993.

CANOTILHO, J. J.GOMES. DIREITO CONSTITUCIONAL E TEORIA DA CONSTITUIÇÃO. 3ª ed. Coimbra: Almedina. 1999.

CARBONERA, Silvana Maria.O PAPEL JURÍDICO DO AFETO NAS RELAÇÕES DE FAMÍLIA. In: REPENSANDO FUNDAMENTOS DO DIREITO CIVIL CONTEMPORÃNEO. FACHIN, Luiz Edson ( Org.).Rio de Janeiro: Renovar. 1998.

62 FREITAS, Juarez. A INTERPRETAÇÃO SISTEMÁTICA DO DIREITO. 3aed. São Paulo: Malheiros.2002. p.91/92.

${ }^{63}$ HERKENHOFF, João Baptista. DIREITO E UTOPIA. 3ª ed. Porto Alegre: Livraria do Advogado. 1999. p.15 
COELHO, Francisco Pereira; OLIVEIRA, Guilherme de. CURSO DE DIREITO DE FAMÍLIA. $2^{a}{ }^{a}$ ed. Coimbra: Coimbra. 2001. vol.1.

DIAS, Maria Berenice. UNIÃO HOMOSSEXUAL. O preconceito \& a Justiça. 2ª ed. Porto Alegre: Livraria do Advogado. 2001.

DWORKIN, Ronald. LEVANDO OS DIREITOS A SÉRIO. São Paulo. Martins Fontes. 2002. . O IMPÉRIO DO DIREITO. São Paulo. Martins Fontes. 1999.

FACHIN, Luiz Edson. DIREITO DE FAMÍLIA. Elementos críticos à luz do novo Código Civil brasileiro. $2^{\underline{a}}$ Ed. Rio de Janeiro: Renovar. 2003. . TEORIA CRÍTICA DO DIREITO CIVIL. Rio de Janeiro: Renovar. 2000.

FREITAS, Juarez. A INTERPRETAÇÃO SISTEMÁTICA DO DIREITO. 3ªed. São Paulo: Malheiros. 2002.

GOMES, Orlando. DIREITO DE FAMÍLIA. 7ª ed. Rio de Janeiro: Forense. 1993.

GONÇALVES FILHO, JOÃO GILBERTO. Ação Civil Pública no 2005.61.18.000028-6, da 1aㅡ Vara Federal de Guaratinguetá/SP. 2005 ( cópia digitada cedida pelo autor)

HERKENHOFF, João Baptista. DIREITO E UTOPIA. 3ª ed. Porto Alegre: Livraria do Advogado. 1999. LEITE, Eduardo de Oliveira.ORIGEM E EVOLUÇÃO DO CASAMENTO in TRATADO DE DIREITO DE FAMÍLIA. Curitiba: Juruá. Vol. 1. 1991.

MATOS, Ana Carla Harmatiuk. UNIÃO ENTRE PESSOAS DO MESMO SEXO: aspectos jurídicos e sociais. Belo Horizonte: Del Rey. 2004.

MORAIS Vinicius. ANTOLOGIA POÉTICA. 25aed. Rio de Janeiro: Livraria José Olympio Editora. 1984.

RIOS, Roger Raupp. A HOMOSSEXUALIDADE NO DIREITO. Porto Alegre: Livraria do Advogado e ESMAFE. 2001. 